\title{
LA PRESCRIPCIÓN DE ACCIONES EN CONFLICTOS VECINALES. UN TEMA EN PERMANENTE DISCUSIÓN
}

Dayán Gabriel López Rojas.

Profesor asistente de Derecho Procesal

Universidad de Matanzas "Camilo Cienfuegos

Yisel Mildrey Torres Castro.

Abogada de la Organización Nacional de Bufetes Colectivos

Heyvis Martínez Niño

Abogada de la Organización Nacional de Bufetes Colectivos

"El tiempo es un poder al cual ningún ser humano puede sustraerse; lo que ha existido largo tiempo, nos aparece sólo por eso como algo firme e inconmovible y es un mal defraudar las expectativas que crea"

WINSCHEID

\section{INTRODUCCIÓN}

La colindancia e, incluso, la mera proximidad de las propiedades, hasta donde llega la zona de influencia de las actividades que en ellas se realizan, hace que los inmuebles queden inevitablemente relacionados entre sí. Estas relación recíproca, que es mucho más estrecha de la que a veces quisieran los propietarios y usuarios que, por cualquier título, disfrutan de tales inmuebles, viene siendo, desde antiguo, un importante foco de tensiones y conflictos porque si es posible delimitar y deslindar con claridad la extensión física de los predios, lo cierto es que las actuaciones de quienes los disfrutan, directa o indirectamente, cruzan con frecuencia los límites físicos de las heredades y repercuten en sus vecinos.

El presente estudio se encamina a analizar los contornos generales que rodean el instituto de las relaciones de vecindad y lo relativo a la prescripción de acciones en esta materia. En este sentido se perfilan los caracteres dogmáticos configurativos de los límites al dominio por razón de la vecindad o colindancia, distinguiéndolos de otro instituto afín cual es la servidumbre; al tiempo que se atiende, en especial, a la problemática que genera la prescripción extintiva en sede de conflictos vecinales. La investigación, que encara la temática examinada desde la óptica de la realidad legislativa cubana, apoya su basamento teórico en la doctrina española, y ello en razón del vínculo histórico-jurídico que nos une ${ }^{1}$. Asimismo se incluyen,

${ }^{1}$ Valga aclarar que Cuba fue uno de los últimos reductos coloniales de España en América. Su independencia de la metrópoli española se produjo en el año 1898, de tal suerte que 
convenientemente, algunos pronunciamientos jurisprudenciales que reflejan las posiciones asumidas por parte de los tribunales cubanos con relación al tema.

\section{LOS LÍMITES DEL DOMINIO POR RAZÓN DE LA PROXIMIDAD O COLINDANCIA: LAS RELACIONES DE VECINDAD. Cuestiones generales}

Constituye un hecho cierto que la vecindad genera conflictos $y$, por tanto, es una exigencia social imponer límites recíprocos a las facultades que le corresponden a cada propietario para que la convivencia se torne lo más pacífica posible ${ }^{2}$. Ante esta situación, y en aras de lograr la armonía social, el ordenamiento jurídico se ha visto obligado a reaccionar delineando normativamente el instituto de las "relaciones de vecindad", definidas como:

"el conjunto de límites o limitaciones al contenido de la propiedad inmobiliaria que, por exigencias de una ordenada convivencia, se establecen en interés de las propiedades contiguas o próximas y de cuantos por cualquier título disfrutan

las monumentales obras jurídicas que regían entonces en ese país se hicieron extensivas a sus colonias de ultramar. Así, el CC español de 1888 -cuya vigencia se hizo extensiva a Cuba en virtud del real decreto de 31 de julio de 1889-, rigió entre nosotros hasta el año 1987 (casi cien años), cuando fue subrogado por la ley $\mathrm{N}^{\mathrm{o}} 59$, de 16 de julio, actual $C C$ de la República de Cuba.

2 Apud. Fernández Martínez (2004), p. 8 . de ellas, y que, en su generalidad, definen el estatuto normal del dominio y el ámbito de las facultades que lo integran"3.

El entendimiento de las relaciones de vecindad como límites al derecho de propiedad -formando parte de su contenido intrínseco- encuentra apoyo en las modernas concepciones que defienden la función social de tal derecho $^{4}$, de la que se hace eco el $C C$ cubano al establecer como premisa:

"todo el que ejerza un derecho sobre bienes o realice alguna función relacionada con éstos, está obligado a hacerlo de modo racional y a tener en cuenta en cada caso el destino socioeconómico del bien de que se trate".

(cfr. art. 132 del $C C$ cubano).

Dentro de los predios del Derecho Civil, a partir de la especialidad del objeto de regulación, se ha ido desarrollando, sin autonomía científica alguna, el doctrinalmente denominado Derecho de Vecindad, cuyo objetivo es definir y fijar estos límites al ejercicio del derecho de propiedad

${ }^{3}$ Fernández Urzaindui (1994), p. 132.

${ }^{4}$ Frente a la concepción individualista de la propiedad, entendida como derecho absoluto o limitado tan sólo por su necesaria coexistencia con otros derechos de igual contenido, ha terminado por imponerse la consideración del dominio como derecho intrínsecamente limitado-o delimitado-por su propia función social, lo que implica que en su ejercicio debe atemperarse a los valores e intereses de la colectividad, es decir, a la finalidad o utilidad social que cada categoría de bienes objeto de dominio esté llamada a cumplir. 
sobre inmuebles derivados de las relaciones de colindancia o proximidad; y no al sólo efecto de corregir los abusos, impedir la persistencia de las ilegítimas injerencias e indemnizar al perjudicado por ellas, sino también, y principalmente, para prevenir y evitar las fricciones entre vecinos, mediante una adecuada ordenación de sus relaciones, sea a través de particulares limitaciones legales definitorias de situaciones permanentes de eficacia real, o a través de formulaciones generales, susceptibles de ulterior concreción, dirigidas, en definitiva, a determinar hasta qué punto está obligado un propietario a tolerar una forma de goce, uso o utilización de la propiedad colindante que le cause molestias o desvalorice la suya.

Las relaciones de vecindad distan de constituir una categoría homogénea. El término mismo 'vecindad' es dable a la confusión, en cuanto designa tanto una relación de proximidad personal durativa como una situación de contigüidad o cercanía entre lugares, parajes o predios. Una y otra vecindad dan vida a relaciones susceptibles de recibir dicha calificación; la segunda, sin embargo, amén de imponer a sus propietarios las exigencias de comportamiento que la convivencia postula, puede llevar aparejada, en los casos de contigüidad predial, una especial configuración del dominio y de las facultades inherentes al mismo ${ }^{5}$.

${ }_{5}^{5}$ Refiriéndose a esta situación ha puesto de relieve Francisco J. Fernández Urzainqui: "la mera colindancia entre fundos y las tensiones a que se hallan expuestos sus propietarios por la natural injerencia de unos en la esfera de los otros, ha venido siendo tomada en consi-
Más allá de estas limitaciones, esencialmente ligadas a la contigüidad o colindancia de los predios; la mera proximidad y la eventual proyección exterior de los usos o actividades que en ellos se desarrollan impone a los propietarios $-\mathrm{O}$ a quienes por cualquier otro título los disfruten, utilicen o posean-, ciertos límites en el ejercicio de sus derechos a fin de posibilitar a los demás el disfrute de los suyos sin causarles perturbación o daño. En estos casos la vecindad no supone la preexistencia de una relación jurídicoreal entre predios, limitativa o conformadora del contenido dominical, pero sí impone deberes de respeto y tolerancia en aras a una adecuada y armoniosa convivencia social.

Sentado lo anterior, cabe entonces distinguir en el ámbito de la institución analizada dos tipos o clases de relaciones vecinales: unas de contenido predeterminado y eficacia real, cuya transgresión legitima al afectado para instar judicialmente el restablecimiento de la situación predial al estado conformado o definido por la ley; y otras de relieve obligacional, cuya infracción autoriza a solicitar, con el cese del uso o actividad perturbadora o dañina, la indemnización de los perjuicios causados.

Las primeras norman y prohíben los comportamientos que afectan la situación fáctica posesoria sobre el

deración por el legislador histórico para fijar, en contemplación a determinadas circunstancias de hecho que la tradición ha revelado conflictivas, ciertas limitaciones, de contenido típico y eficacia real, enderezadas a prevenir y evitar controversias vecinales que, por su misma generalidad, conforman el contenido mismo del dominio interpredial". FERnÁndez URZAinQUI (1994), p. 133. 
inmueble, vinculadas por tanto a las denominadas inmisiones directas -las construcciones invasivas, por ejemplo (cfr. art. 175 del $C C$ cubano). Las segundas, por el contrario, no suponen desposesión para el perturbado y son las relacionadas con las inmisiones indirectas, como acontece en los supuestos de los olores, ruidos, humedades, que teniendo su origen en el fundo vecino afectan al colindante.

Con admirable precisión, la doctrina ha ido delineando los caracteres generales de esta figura, lo que ha servido para establecer las distinciones con las servidumbres, instituto afín con el que se les suele confundir. Así, se ha entendido que las relaciones de vecindad responden a las siguientes características ${ }^{6}$ :

$1^{\circ}$ Son inherentes y consustancia312 les a la propiedad inmobiliaria y nacen espontáneamente, sin necesidad de acto constitutivo alguno, por el mero presupuesto de que existan predios contiguos o próximos pertenecientes a propietarios distintos.

$2^{\mathrm{O}}$ Operan en régimen de igualdad y reciprocidad sobre todos los propietarios y usuarios de inmuebles, de tal suerte que la limitación que cada propietario sufra en el ejercicio de su derecho encuentra su justa compensación en la correlativa limitación del derecho de su vecino. $\mathrm{O}$, visto desde el punto de vista contrario, la ventaja

${ }^{6}$ Sancho Rebullida (1967), p. 200; LaCruz Berdejo (2008), p. 331; Fernández URZAINQUi (1994), p. 137. que como usuario de un inmueble obtenemos sobre la finca disfrutada por nuestro vecino lleva aparejada la facultad de éste para obtener la misma utilidad sobre la nuestra.

$3^{\circ}$ Salvo disposición legal expresa, todas las limitaciones legales del dominio impuestas por las relaciones de vecindad son susceptibles de regulación convencional por los interesados, siempre que con ello no se cause un perjuicio a terceros. Ahora bien, sólo si mantienen el régimen de reciprocidad se podrá continuar hablando de una nueva regulación de las relaciones vecinales, pues si se pierde tal reciprocidad y, en consecuencia, una finca pasa a ser subordinada de la otra, entonces la regulación pactada quedará fuera del estatuto normal de la propiedad y de las relaciones de vecindad para configurar una servidumbre.

$4^{\mathrm{O}}$ Las relaciones de vecindad, a diferencia de lo que acontece respecto a algunas servidumbres, son imprescriptibles (no usucapibles); y ello así porque configuran el contenido normal del derecho de propiedad, lo que determina que las limitaciones legales impuestas para preservar las buenas relaciones de vecindad se consideren públicas y liberadas de toda prueba o inscripción en algún registro público para ser opuestas frente a terceros. 


\section{RELACIONES DE VECINDAD Y SERVIDUMBRES. UNA MIRADA DESDE EL $C C$ CUBANO}

Una problemática común en sede de límites y limitaciones al derecho de propiedad ha sido la confusión entre las figuras de las relaciones de vecindad y las servidumbres prediales, lo que en nuestro medio legislativo ha venido determinado, sin duda, por la defectuosa regulación legal que históricamente se le ha ofrecido al tema.

El $C C$ español de 1888 -cuya vigencia se hizo extensiva a Cuba en virtud del real decreto de 31 de julio de 1889- no estableció diferenciaciones entre estas instituciones, y bajo el rubro de "servidumbres" reguló auténticos límites del dominio por razón de vecindad ${ }^{7}$.

${ }^{7}$ Así lo reconocen Luis Díez-Picazo y Antonio Gullón, quienes ha puesto de manifiesto que la distinción entre servidumbres y relaciones de vecindad aparece oscurecida en la sistemática del $C C$ español por cuanto se han regulado, entre las servidumbres, las siguientes limitaciones: $1^{\mathrm{a}}$. La de consentir el paso de materiales por la finca, cuando fuese indispensable para construir o reparar algún edificio, o la de soportarla colocación de andamios y otros objetos (art. 569); $2^{\mathrm{a}}$. La de recoger las aguas pluviales de manera que recaigan sobre suelo propio o sobre suelo público (art. 586); $3^{\mathrm{a}}$. La de soportar la caída de las aguas que desciendan naturalmente y sin obra del hombre de los predios superiores (art. 552); $4^{\text {a }}$. La de guardar las distancias prevenidas en los art. 581 a 583 para abrir ventanas, balcones y otros voladizos sobre la finca del vecino, ya con vistas rectas, ya con vistas oblicuas; $5^{\mathrm{a}}$. La de guardar las distancias en las plantaciones y construcciones que fijan los artículos 589 a 592; 6 a . Las que pesan sobre los propietarios de una pared, muro, seto, valla, etc., medianera (arts. 571 a 579); $7^{\mathrm{a}}$. La de permitir al propietario de un enjambre de abejas que lo persiga en finca ajena (art. 612),
Es válido destacar que, aunque ambas tienen como punto coincidente su vinculación con el derecho real de propiedad sobre bienes inmuebles, constituyen figuras absolutamente independientes, lo que viene determinado por la naturaleza jurídica de cada una de ellas. Mientras las relaciones de vecindad constituyen límites intrínsecos del derecho de propiedad sobre bienes inmuebles, cuyo ejercicio queda configurado en virtud de las normas que regulan los derechos de exclusión y los deberes de tolerancia que se imponen a los propietarios vecinos ${ }^{8}$; las servidumbres consisten en un derecho real limitado $^{9}$ que confiere a su titular un beneficio o utilidad sobre una cosa ajena (ius in re aliena).

En orden a la adecuada distinción de estas figuras, la doctrina ha sistematizado un grupo de criterios en forma de patrones comparativos. $\mathrm{Al}$ respecto se ha entendido que las relaciones de vecindad forman parte del régimen normal de la propiedad inmobiliaria en tanto restricciones internas del Derecho de Propiedad, mientras que las servidumbres suponen una limitación anormal y extrínseca del dominio ajeno; las primeras se establecen con carácter general, igualitario y recíproco, mientras que las servidumbres constituyen un derecho real limitado que genera una relación interpredial jerarquizada, con un predio dominan-

\footnotetext{
aunque esta obligación no se circunscribe exclusivamente al propietario vecino. Véase Diez PICAZO y Gullón (1997), p. 165.

${ }^{8}$ Hernández Gil (1985), p. 6.

${ }^{9}$ Díez-Picazo y Gullón (1997), pp. 382 y 436 .
} 
te y otro sirviente. Las relaciones de vecindad son inherentes a los fundos y se incorporan a ellos en forma directa por la ley, mientras que las servidumbres precisan la aplicación del precepto legal mediante acto constitutivo; las limitaciones por razón de vecindad no están sujetas a prueba e inscripción registral para su oponibilidad a terceros, mientras que las servidumbres han de probarse y, salvo las manifiestas, no perjudican a tercero por su no inscripción; las relaciones de vecindad no originan derecho a indemnización y sí las servidumbres legales, por la reducción del contenido del derecho de propiedad que sufre el propietario de la finca sirviente en beneficio del predio dominante.

Empero, las limitaciones del dominio por razón de la vecindad no 314 generan sólo una relación real entre propietarios de predios, como las servidumbres, sino que exigen un comportamiento de los usuarios de los predios vecinos, sean o no propietarios, cuya observancia y transgresión se desenvuelve en el ámbito meramente obligacional.

El legislador cubano de 1987, por su parte, incurrió en similar imprecisión a la que en su momento se cometió en la regulación contenida en el código ibérico; y es así que por motivaciones de ideología política, en el $C C$ cubano de 1987 se suprimió toda referencia al vocablo servidumbre -para evitar cualquier asociación con la idea de explotación e injusticia- siendo lo cierto que en el marco de la regulación normativa de las denominadas "limitaciones derivadas de las relaciones de vecindad" se tutelan clásicas servidumbres como lo es la de paso necesario (cfr. art. 171 del $C C$ cubano). Sobre este particular ha expresado el profesor Orlando Rivero Valdés:

"muchos consideran y divulgan la tesis de que, desde 1988, en el Derecho Civil cubano han desaparecido las servidumbres, o que lo que era servidumbre ahora es limitación derivada de las relaciones de vecindad. Y es oportuno recordar que el codificador civil lo que hizo fue esto último: donde estaba el título servidumbre, puso el de relaciones de vecindad incurriendo en el error doctrinal de los textos civiles post napoleónicos pero a la inversa" ${ }^{10}$.

Es oportuno razonar, sin embargo, que las imprecisiones que haya podido cometer el legislador en modo alguno pueden provocar una desnaturalización de estas instituciones al punto que conlleve a su confusión; pues ello implicaría mezclar los efectos jurídicos derivados de una y otra que, obviamente, son diferentes.

\section{LA PRESCRIPCIÓN DE ACCIONES. Notas ESENCIALES}

El transcurso del tiempo, entendido como hecho natural, genera consecuencias jurídicas; y esta problemática que en términos amplios es abordada por la parte general del Derecho Civil, también recibe especial atención

\footnotetext{
${ }^{10}$ Cfr. Rivero Valdés (2003), p. 77.
} 
por parte de otras materias específicas cuando se estudian figuras cuya virtualidad está determinada por el paso de un período temporal, como ocurre, por ejemplo, con el instituto de la usucapión, propio del Derecho sobre Bienes.

Sin embargo, la relevancia del paso del tiempo no es sólo atendible desde la óptica del derecho sustantivo; sus efectos también operan en sede procesal, de lo cual la figura jurídica de la prescripción extintiva -también denominada prescripción de acciones- constituye una prístina manifestación en tanto medio defensa oponible por el demandado con el propósito de aniquilar la acción contra él ejercitada si previamente ha quedado configurado lo que la doctrina ha denominado como silencio de la relación jurídica ${ }^{11}$. Así, el $C C$ cubano establece en el art. 112:

\section{"Las acciones civiles prescri- ben cuando no son ejercitadas dentro de los términos fijados en la ley".}

La prescripción extintiva no halla justificación en la idea de justicia, pues en sentido general la finalidad de este instituto tiende a permitir la consolidación de situaciones que, en

${ }^{11}$ La prescripción extintiva se configura como un hecho excluyente que, partiendo de la existencia del derecho afirmado por el actor, opera frente a éste como un contra-derecho otorgado al demandado para enervar la acción ejercitada, oponible como excepción material o perentoria cuya estimación provoca el rechazo en cuanto al fondo de la pretensión deducida. Cfr. arts. 236 y 495.5 de la Ley de Procedimiento Civil, Administrativo, Laboral y Económico. su origen, eran contrarias a la ley, desplegando su eficacia ante la postura de abandono, negligencia o indiferencia que asume el titular de un derecho subjetivo al desentenderse de su ejercicio durante el tiempo que fija la ley, configurándose, de este modo, el "silencio de la relación jurídica" ${ }^{12}$; de tal suerte que frente a esta situación el ordenamiento jurídico, con el propósito de tutelar situaciones que se presentan con manifiesta estabilidad temporal, prevé, -cual especie de sanción- la figura en comento, fundamentándola en los principios de certidumbre y seguridad jurídica $^{13}$.

${ }^{12}$ Díez-Picazo (1964), p. 83. Sostiene que el denominado silencio de la relación jurídica implica la falta de ejercicio del derecho por parte de su titular (silencio del sujeto activo) y la falta de reconocimiento de aquél por parte del deudor (silencio del sujeto pasivo). Sobre el fundamento de la prescripción extintiva se ha pronunciado en la doctrina patria el profesor Vicente Rapa Álvarez para quien este instituto "actúa como un acicate para que los derechos se ejerzan oportunamente, pues a medida que pasa el tiempo se torna más difícil probar su existencia o su nacimiento, considerándose conveniente el establecimiento de un límite temporal a la tutela jurídica de los mismos". Véase Rapa Álvarez (1998), p. 205.

${ }^{13}$ De esta opinión, José F. Valls Gombau, quien sostiene que la prescripción extintiva representa un equilibrio entre la seguridad jurídica y la justicia material. Véase VALLS Gombau (1995), p. 418. Sobre el fundamento de la analizada institución se pronunció el Tribunal Constitucional español en su sentencia $\mathrm{N}^{\circ} 147$, de 25 de noviembre de 1984, en la que se razonó: “...la prescripción, forma de extinción de las acciones para la defensa de un derecho cuyo origen está en lo que la doctrina ha llamado "silencio de la relación jurídica", es una figura estrechamente conectada con la idea de seguridad jurídica, porque, para garantizarla, puede llegar a permitir la consolidación de situaciones que, en su origen, eran contrarias a la ley cuando el titular de una 
Si bien se ha afirmado, para ofrecer cumplida justificación a la prescripción extintiva, que constituye una exigencia de la seguridad jurídica la limitación del ejercicio tardío de los derechos; algún sector jurisprudencial -especialmente en España- se ha pronunciado en el sentido de proponer que esta figura sea objeto de una interpretación restrictiva con apoyo en la idea de que no son criterios de justicia intrínseca los que informan el instituto ${ }^{14}$.

Una cuestión que durante mucho tiempo generó enconadas discusiones en el escenario doctrinal, y que aún provoca confusiones en la práctica jurisdiccional, es la que tiene que ver con el significado de la prescripción extintiva y el verdadero alcance de los efectos que despliega, pues se discutía sin llegar a acuerdo sobre si lo que realmente prescribía era la acción o el derecho subjetivo ${ }^{15}$.

De la mano de las evolucionadas concepciones en torno al concepto de acción como categoría procesal -entendida como la facultad de exigir la tutela concreta de un determinado derecho subjetivo o de una parte de su contenido $^{16}$ - la polémica se ha clarificado al punto de que en la actualidad

pretensión no la ejercita en un plazo de tiempo que pueda considerarse razonable desde la perspectiva de la buena fe. Como la doctrina ya ha observado, en el seno de la institución de la prescripción existe un equilibrio entre las exigencias de la seguridad jurídica y las de la justicia material, que a veces ha de ceder para dar paso a aquélla y permitir un adecuado desenvolvimiento del tráfico jurídico...”.

${ }^{14}$ Apud. García Cantero (1995), p. 13.

${ }^{15}$ Sobre este particular, véase Albaladejo (2002), pp. 891-892.

${ }^{16}$ Díez-Picazo et al. (1991), p. 2150. la posición doctrinal mayoritaria asume que la figura de la prescripción extintiva se dirige, en puridad, a impedir el ejercicio de la acción sin afectar el contenido material del derecho subjetivo alegado. Ello implica que los efectos del instituto no desdicen en modo alguno la faz sustantiva del Derecho, sino que, únicamente, provocan el decaimiento de la posibilidad de defenderlo en la vía jurisdiccional ${ }^{17}$. Nos enseña Luis Díez-Picazo que la prescripción extintiva no afecta de modo directo e inmediato al Derecho Subjetivo considerado como unidad de poder. Prescriben, en puridad, las facultades jurídicas que componen el Derecho Subjetivo, en concreto, las "facultades de exigir", entendidas como los distintos poderes jurídicos que permiten exigir una conducta de otro ${ }^{18}$.

Tal entendimiento supone que aun habiéndose configurado los presupuestos de la prescripción, y existiendo un pronunciamiento judicial que así lo

${ }^{17}$ Así lo ha reconocido la jurisprudencia patria y así se advierte en el pronunciamiento contenido en la sentencia $\mathrm{N}^{\circ} 620$, de 27 de septiembre de 2005, dictada por la Sala de lo Civil y lo Administrativo del Tribunal Supremo Popular, en la que se razonó: “...el Código Civil se refiere a la prescripción de acción y no de derecho, por lo cual aun cuando en determinada norma distinta se tutele un determinado derecho, el transcurso del tiempo establecido en los artículos ciento catorce al ciento diecisiete, según el objeto de que se trate, lo que lleva aparejado consecuentemente es la prescripción de la acción, lo que equivale a que cuando legalmente el derecho aparezca refrendado en esa norma, no puede hacerse valer ante el Tribunal, cuando el derecho subjetivo quede con vida, y sólo podría reclamarse extrajudicialmente (...)". Véase PérEZ GALLARDO (2001), pp. 126-127.

${ }^{18}$ Díez-Picazo (1964), p. 35. 
declare, todavía el derecho subjetivo puede continuar desarrollando sus efectos interpartes; de modo tal que su cumplimiento por el sujeto pasivo que ganó en su favor la prescripción nunca se entendería indebido por considerarse una obligación natural ${ }^{19}$.

$\mathrm{Al}$ constituir un hecho excluyen$\mathrm{te}^{20}$ de la pretensión del actor, su apreciación en un proceso determinado estará sujeta a la alegación oportuna de quien resulte favorecido por ella sin que proceda la apreciación ex officio por el órgano jurisdiccional. Según explica Karl Larenz, sus efectos se producen únicamente ope excepcionis, nunca ope $\operatorname{legis}^{21}$.

${ }^{19}$ De esta opinión: De la Oliva Santos y Fernández López (1990), p. 104; Díez-Picazo (1964), p. 28; Valls Gombau (1995), p. 427.

${ }^{20}$ Refiriéndose al significado y alcance procesal de los hechos excluyentes explica José F. Valls Gombau: "Aun cuando la pretensión sea debida, los hechos excluyentes no la niegan, sino que oponen, mediante su alegación, otros eventos que resultan contrarios y cuya concurrencia comporta su rechazo. Este no se produce porque los hechos alegados por el actor sean falsos, sino en tanto que los justificados por el demandado le permiten excluir o paralizar la prestación debida". Véase Valls Gombau (1995), p. 428.

${ }^{21}$ Larenz (1978), p. 328. El Tribunal Constitucional español definió en la sentencia $\mathrm{N}^{\circ}$ 215, de 21 de diciembre de 1989: “...se trata de una auténtica excepción sólo oponible por la parte, en cuanto introduce un hecho nuevo (principio de aportación, iudex iudicare debet secundum allegata partium) que debe ser conocido por la contraria para que se cumpla el principio de contradicción. No hacerlo así, o ser traído y apreciado el hecho por el Juez, constituye una infracción de las normas que rigen el adecuado y correcto proceso". Cfr. Valls Gombau (1995), p. 427. En este propio sentido se ha pronunciado la Sala de lo Civil y lo Administrativo del Tribunal Supremo Popular, de lo que da muestras la sentencia $\mathrm{N}^{\circ} 109$, de 31 de marzo de 2008, que en lo atinente dispuso:

\section{a) La prescripción de acciones en sede de conflictos vecinales. Posiciones doctrinales}

Un extremo de singular polémica en sede de relaciones de vecindad es lo relacionado con la prescriptibilidad o no de la acción para exigir la correcta observancia de las relaciones de vecindad. En la doctrina española -donde éste está muy lejos de ser considerado un tema pacífico-, se encuentran pronunciamientos jurisprudenciales en uno y otro sentido.

Una fuerte posición teórica ha sustentado desde antaño el criterio de que no se extinguen por prescripción las acciones tendentes a procurar el cabal cumplimiento de las relaciones vecinales, en el entendido de que los actos realizados y soportados en este ámbito se presumen de mera tolerancia.

Quienes siguen esta línea de pensamiento interpretan, apoyados en la naturaleza jurídica de las relaciones de vecindad, que si aquéllas componen el contenido del Derecho de Propiedad entonces mientras éste se mantenga, se conservará el derecho de pedir que sea respetado sin que en ello tenga alguna influencia el paso del tiempo. Así entienden, por ejemplo, que si el propietario sobre cuyo fundo vuelan las ramas del árbol ajeno no hace uso

"La prescripción (...) a diferencia de la caducidad no puede ser apreciada de oficio por el Tribunal, sino sólo es estimable cuando es alegada por las partes, entonces debe entenderse que el éxito del ejercicio de una acción depende en gran medida de haberse ejercitado oportunamente, ello por la necesidad que tiene la sociedad de dar estabilidad y juridicidad a ciertas situaciones de hecho convirtiéndolas en situaciones de Derecho (...)". Véase Pérez Gallardo (2001), p. 127. 
de su derecho a reclamar que se corten, la norma realiza la presunción de que es una situación de mera tolerancia. El paso del tiempo no consolidará derecho alguno para el propietario del árbol que realiza el acto, ni impedirá que se ejercite por el propietario que lo soporta (tolerante), el derecho a reclamar el cumplimiento de la norma. ${ }^{22}$

Esta posición ha merecido en los últimos tiempos una revisión de su fundamento, y frente a ella se ha erigido una postura doctrinal que sostiene el criterio de que ciertamente las acciones que tiene por objetivo exigir el cumplimiento de las relaciones de vecindad resultan prescriptibles. Para ello se parte de someter a revisión el enfoque ofrecido por la posición contraria argumentando, en este sentido, que en realidad resulta preciso distinguir entre "derecho subjetivo" -considerado como unidad de poder- $y$ "facultad de exigir" vinculada a él-entendida como poder jurídico que permite requerir de otro un actuar determinado-; razonando que el paso del tiempo no produce en realidad afectación alguna sobre el derecho en sí mismo, sino sobre la facultad de defenderlo en la vía jurisdiccional frente a perturbaciones consentidas, quedando su titular a expensas de que quien ganó la prescripción cumpla de modo convencional la obligación natural de respetarlo ${ }^{23}$.

${ }^{22}$ Véase SAnagustín Sánchez (2011), p. 105. Refiere este autor que son numerosas las sentencias que definen la relación de vecindad como “(...) acto meramente tolerado y potestativo que no engendra derecho alguno en quien lo realiza ni obligación en quien lo soporta".

${ }^{23}$ Es este el criterio que ha sostenido la práctica judicial cubana y con el que coinciden los autores de este estudio.

Pedro de Pablo Contreras recrea de modo diáfano esta postura cuando explica:

"la prescripción tiene por objeto las correspondientes acciones protectoras, en el sentido sustantivo de pretensiones, o sea, las facultades de exigir una determinada conducta de una persona igualmente determinada (...). Por lo tanto, en estos casos, invocando con éxito la prescripción se detiene la concreta pretensión o acción ejercitada, pero no se extingue necesariamente el derecho (para lo que sería preciso que hubieren prescrito todas y cada una de las pretensiones que nazcan del mismo), que podrá hacerse valer frente a cualquier otro vulnerador de él que no sea sucesor en sentido jurídico del primero" ${ }^{24}$.

\section{b) El dies a quo del plazo prescriptivo}

Siendo el transcurso de un determinado plazo el componente básico sobre el que opera la prescripción extintiva, se entiende que una de las cuestiones capitales y más complejas que rodea esta institución sea la de determinar el momento exacto en que dicho plazo empieza a correr.

${ }^{24}$ De Pablo Contreras (1995), p. 96. Y en este propio sentido se pronuncia Francisco J. Fernández Urzainqui, quien sostiene: "la prescripción no determina la automática extinción del derecho, sino que confiere al sujeto favorecido por ella la facultad de oponerla a la tardía pretensión de hacerlo efectivo", FERNÁNDEZ URZAINQUi (1995), p. 263. 
La doctrina es unánime en fijar la ejercitabilidad de la acción como presupuesto básico o punto de partida del plazo para la prescripción. Así se entiende que para que pueda comenzar a contarse el plazo de prescripción es necesario que la acción haya nacido, pues la acción todavía no nacida no prescribe (actio nondum nata no praescribitur); y según Luis Díez-Picazo, el nacimiento de la acción coincide con el nacimiento del derecho, pues todo derecho subjetivo, desde su nacimiento, va acompañado de las correspondientes acciones para su ejercicio y defen$\mathrm{sa}^{25}$. Tal posición ha sido asumida por el $C C$ cubano que refrenda en el art. 120:

"El término de prescripción se cuenta desde que la acción pudo ser ejercitada”.

Resulta necesario, entonces, definir el instante en que surge tal posibilidad de ejercicio; y en tal sentido la doctrina se ha inclinado resueltamente por considerar que ello debe determinarse sobre bases abstractas y objetivas, sin atender en ningún modo a cuestiones subjetivas y personales, de modo que coincidimos con Manuel Albaladejo cuando sostiene:

"para juzgar del comienzo de la prescripción hay que tener en cuenta simplemente si la acción es 'legalmente' ejercitable, sin que importe que de hecho no pueda ser interpuesta por su titular, porque eso no afecta a que la acción exista y la pres-

${ }^{25}$ Díez-Picazo (1964), p. 82. cripción comience su curso"26. Al respecto ha entendido Alberto Melucci:

"el momento inicial de la prescripción es aquél en el cual surge un estado de hecho que constituye una contradicción del derecho; contradicción que unas veces consistirá en la violación o perturbación del derecho, y otras en su mera insatisfacción o incumplimiento" 27 .

26 Albadalejo (1993), p. 574. De igual criterio Luis Díez-Picazo, para quien: "una imposibilidad puramente subjetiva no es nunca tomada en consideración, ni por ella queda impedido el comienzo de la prescripción (...) de modo que, a efectos de la prescripción, son irrelevantes: 1) la imposibilidad material en que una persona se encuentra para ejercitar una acción, sea por hallarse ausente, incomunicado o físicamente imposibilitado para dirigirse contra el demandado; 2) el desconocimiento del titular del derecho respecto a la posibilidad de ejercicio". Cfr. Dítz-Picazo (1964), p. 86. Éste ha sido igualmente el criterio seguido por la jurisprudencia española, la que ha reiterado en numerosas sentencias, según pone de manifiesto Francisco Muñoz Jiménez, que la posibilidad a que alude el art. 1969 del $C C$ español (análogo al art. 120 del $C C$ cubano) es la "legal", independizada de toda condición o circunstancia subjetiva del interesado, las que sólo pueden tenerse en cuenta cuando la ley así lo determina. Véase MuÑoz Jiménez (1995), p. 188.

${ }^{27}$ Citado por Luis Díez-Picazo quien sostiene, en este propio sentido: "el derecho comienza a prescribir desde que es violado, pues en ese momento puede y tiene que ejercitarse la acción para protegerlo; y que es violado en unos casos cuando un tercero lo lesiona mediante un comportamiento positivo y en otros cuando queda insatisfecho por un comportamiento omisivo de un tercero". DítzPicazo (1991), p. 2167. 
Sobre inicio del cómputo del plazo prescriptivo de la acción para reclamar perturbaciones derivadas de las relaciones de vecindad se pronunció la Sala de lo Civil y lo Administrativo del Tribunal Supremo Popular en virtud de la sentencia $\mathrm{N}^{\circ} 1012$, de 28 de septiembre de 2001, y en lo atinente valoró:

“(...) según la recurrente, aunque la referida resolución judicial establece, con vistas a la escritura Pública Notarial, por la que su contendiente en la litis adquirió la vivienda en la que se encuentran las ventanas controvertidas, derivan el comienzo del término de prescripción cuyo decurso sostiene el fallo combatido, porque según aduce fue dicha fecha en la que comenzó la perturbación de las relaciones de vecindad, haciendo abstracción del hecho que sostiene el fallo y que es suficiente por mantenerlo cual es que las ventanas discutidas habían comenzado a construirse en los años 1992 y 1995, fechas obviamente anteriores a la data en que se suscribió la antes referida escritura. Vale decir que la impugnante en puridad pretende derivar el comienzo del término de prescripción de la acción, no como corresponde por su carácter real, sino a partir del inicio de las molestias, que fue cuando, para ella, se hicieron patentes, lo que no es válido habida cuenta que implicaría darle a la expresada acción, entidad distinta (...).
Que el motivo segundo del recurso debe correr la propia suerte que el anteriormente resuelto pues, sienta el inicio de la perturbación que en el caso discute no desde la fecha de su inicio como resulta obligado a tenor de lo que preceptúa el Artículo 120 del Código Civil, conforme al cual el término de prescripción comienza a decursar desde que la acción pudo ser ejercitada, sino a partir de que se reanudaron obras para terminar las ventanas discutidas y se ocupó la vivienda en que están enclavadas, lo que sostiene en el hecho de que es en esta oportunidad en la que se inició la perturbación, razonamiento que necesariamente implica dar a aquella carácter personal, contrario al que en puridad disfruta (...)"28.

\section{c) La mera tolerancia y su pretendida eficacia excluyente de la prescripción extintiva en conflictos vecinales}

En la práctica diaria es común escuchar, en sede de conflictos vecinales, criterios que sostienen que los actos o situaciones tolerados por el propietario impiden que se configure la prescripción de la acción, lo que apoyan en el fundamento de ley contenido en el art. 200 del $C C$ que establece:

"los actos meramente autorizados por el titular de la posesión no generan derecho alguno y

${ }^{28}$ Véase Boletín del Tribunal Supremo Popular (2001), pp. 98-99. 
deben cesar tan pronto aquel manifieste su voluntad en contrario".

Sin embargo, tal postura no parece corresponderse con el ámbito de eficacia que posee la mera tolerancia. Según se advierte al repasar la doctrina científica, la teoría de los actos tolerados establece, en esencia, que éstos no pueden servir como fundamento para la adquisición legítima de la posesión en tanto las situaciones de hecho que se producen en virtud de ellos no generan verdadera posesión sino simple detentación ${ }^{29}$.

Ciertamente los actos tolerados se relacionan con una figura clásica dentro del Derecho sobre Bienes, de origen romano, cuyo principal fundamento descansa también en el paso del tiempo: la prescripción adquisitiva o usucapión ${ }^{30}$, respecto a la cual aquellos operan en el sentido de impedir su configuración.

La prescripción adquisitiva o usucapión constituye un modo de adquirir la propiedad que atiende a la posesión, la conducta y la actividad del poseedor durante un determinado período; mientras que, por el contrario, la prescripción extintiva no implica la adquisición de un derecho sino que se erige en forma de extinción de las acciones para la defensa de un derecho cuyo origen está

${ }^{29}$ La detentación o "poder de hecho" se define como una situación material donde un sujeto tiene el control directo e inmediato de un bien, y constituye un elemento de la posesión. Pero cualquier estado de detentación no califica per se como posesión porque ésta, además, exige que ese poder de hecho se funde en causa legítima. Cfr. art. 196 del $C C$ cubano.

${ }^{30}$ Cfr. arts. 184 al 190 del $C C$ cubano. en lo que la doctrina ha denominado "silencio de la relación jurídica"31.

La posesión legítima -con justo título- es un requisito indispensable para que se cobre virtualidad jurídica la usucapión ${ }^{32}$, y queda excluido como antes se explicó frente a situaciones puramente consentidas por el titular del derecho de propiedad; pero comoquiera que ello no tiene ninguna relación con la prescripción extintiva,

${ }^{31}$ Desde épocas romanas se distinguió nítidamente entre una y otra institución. Así, explica Álvaro D'ors: "la usucapión suponía la adquisición de la propiedad civil por medio de la posesión continuada. Es una forma de apropiación posesoria como la traditio, pero de derecho civil y por tanto, excluida para los extranjeros y para los fundos no itálicos"; mientras que la prescripción tuvo un origen distinto: "En provincias, donde la usucapión no era posible, se admitió que el poseedor que hubiera poseído sin perturbación durante diez años (o veinte si el propietario vivía en otra ciudad distinta) quedara protegido frente a la reclamación del propietario mediante un especie de excepción procesal que recibe el nombre de 'prescripción"”. Apud. D'ors (1968), pp. 178 y 186.

32 Así lo ha ratificado la Sala de lo Civil y de lo Administrativo del Tribunal Supremo Popular de la República de Cuba en varios pronunciamientos judiciales. Passim. Sentencia N ${ }^{\circ}$ 160, de 21 de marzo de 2006, en la que se razonó: “...si bien la prescripción adquisitiva comúnmente conocida por el término usucapión, del latín usucapio, resulta ser una de las formas de adquirir la propiedad por el uso, para su éxito en proceso no basta con la demostración de la posesión quieta y pacífica por el término establecido en la Ley sustantiva, pues ello por sí solo constituye tolerancia, lo cual no genera derecho alguno, sino que se requiere además la concurrencia de otra circunstancia, a saber, poseer a título de dueño, consideración que no puede equipararse a la creencia que de tal situación tenga sólo el poseedor, e incluso los vecinos del lugar, sino que ello presupone esencialmente que en su momento se hubiere tratado de una transmisión legítima, consiente con tal propósito, y sobre todo, por quien estaba facultado para ello (...)”.Véase PérEz Gallardo (2001), p. 185. 
que sólo exige el paso del tiempo sin ningún otro requisito adicional vinculado a la posesión, es fácil comprender que la doctrina de los actos tolerados no despliega su eficacia sobre esta institución.

En apoyo de esta conclusión se alza la propia sistemática legislativa que sobre la materia comentada ha regido en el contexto patrio, distinguiéndose siempre en sede normativa entre prescripción adquisitiva y extintiva.

El $C C$ español dedicó el título XVIII -De la prescripción- a regular todo lo concerniente a la adquisición por el paso del tiempo del dominio y demás derechos reales $\mathrm{y}$, asimismo, a la pérdida de las acciones ${ }^{33}$.Así, mientras en el capítulo I del aludido título -dedicado a las Disposiciones Generales- se perfilaron en detalles los contornos legales del instituto de la usucapión, en el capítulo II -De la prescripción del dominio y demás derechos reales- definió el legislador ibérico los requisitos y presupuestos exigibles para que esta institución quedara configurada, a saber: poseer la cosa con buena fe y justo título por el tiempo determinado por la ley, exigiéndose en todo caso que tal posesión fuera en concepto de dueño, pública, pacífica y no interrumpida ${ }^{34}$. En este propio contexto se aclaró ex art. 1942:

"No aprovechan para la posesión los actos de carácter posesorio, ejecutados en virtud de

${ }^{33}$ El legislador ibérico definió en el art. 1930: "Por la prescripción se adquieren, de la manera y con las condiciones determinadas en la ley, el dominio y demás derechos reales".

${ }^{34}$ Cfr. arts. 1940 y 1941 del $C C$ español.

licencia o por mera tolerancia del dueño".

De este escenario normativo se advierte cómo el codificador decimonónico, con adecuado tino legislativo, situó la regulación de la mera tolerancia justo en el espacio dedicado a la figura de la prescripción adquisitiva, para dejar establecido que las situaciones posesorias meramente consentidas impiden la configuración de este instituto.

La regulación de la prescripción extintiva la residenció el legislador español en el capítulo III -De la prescripción de las acciones-, disciplinando exhaustivamente el plazo de prescripción de las acciones según la naturaleza de los derechos a defender; sin que se hiciera alusión alguna a la eficacia que pudieran tener sobre esta figura los supuestos de mera tolerancia.

El $C C$ cubano de 1987, sucesor del longevo cuerpo legal español, tutela la prescripción adquisitiva en el libro segundo -Derecho de propiedad y otros derechos sobre bienes-, ubicándola en el título II, capítulo v, como forma de adquisición de la propiedad bajo la denominación de usucapión; y, en esencia, reproduce la regulación contenida en la legislación española en punto a sus requisitos. Sin embargo, a diferencia del criterio sistemático seguido por su predecesor, el $C C$ cubano no hace alusión a la doctrina de los actos meramente tolerados dentro del articulado que delinea la prescripción adquisitiva; sino que, con una técnica más refinada, regula lo relativo a la mera tolerancia en el espacio que dedica a la posesión como derecho real autónomo, al que se dedica el capítulo 
I del título III -Otros derechos obre bienes-. Así, el legislador cubano de 1987 dispuso en los arts. 199 y 200 que los actos meramente tolerados o autorizados por el titular de la posesión no afectan aquélla ni generan derecho alguno y deben cesar tan pronto aquél manifieste su voluntad en contrario ${ }^{35}$.

De igual forma, el Código en uso regula en el libro I, dedicado a la relación jurídica, el instituto de la prescripción extintiva; y dentro de él destina el título VIII a la prescripción de acciones. Según la disposición contenida en el art. 112:

\section{"Las acciones civiles prescri- ben cuando no son ejercitadas dentro de los términos fijados en la ley".}

Repasando el contenido de las regulaciones contenidas en este título se advierte que, en congruencia con la misma postura asumida por la ley española, tampoco encuentra ninguna alusión a la influencia que pudieran tener las situaciones de mera tolerancia sobre el plazo prescriptivo de las acciones.

De las razones doctrinales argüidas, apoyadas, además, en la interpretación histórico-lógica desarrollada sobre el marco normativo que ha sustentado las figuras objeto de este estudio, es forzoso concluir que ninguna relación existe entre el instituto de la prescripción extintiva y la doctrina de los actos meramente tolerados que, sólo se vincula a la posesión y, en consecuencia, al instituto de la prescripción adquisitiva o usucapión.

Alegada, entonces, en términos hábiles la excepción de prescripción de

\footnotetext{
${ }^{35}$ Cfr. arts. 199 y 200 del $C C$ cubano.
}

la acción frente a una pretensión deducida en un proceso sobre limitaciones derivadas de las relaciones de vecindad, jamás podrá ser desestimada aquélla sobre la base de que la actuación del demandado se inscribe dentro de los actos meramente tolerados, pues quien la opone no pretende adquirir un derecho por prescripción adquisitiva, sino impedir la defensa de aquél en la vía jurisdiccional como consecuencia de haberse perjudicado, por el paso del tiempo, la facultad de exigir que respecto a él ostentaba el actor.

\section{IDEAS CONCLUSIVAS}

Adentrarse en el estudio de una problemática jurídica, aun cuando prima facie luzca como una de las más manidas y cotidianas en la práctica diaria, revela siempre aristas clarificadoras sobre aquellas posiciones tradicionalmente asumidas, al tiempo que permite replanteárselas con apoyo en modernos y avanzados criterios que nutren la Ciencia del Derecho. Luego de haber desarrollado el presente estudio, y a modo de ideas conclusivas, pueden reseñarse las siguientes:

Las relaciones de vecindad constituyen límites al derecho de propiedad sobre inmuebles -formando parte de su contenido intrínseco- a partir de la situación de proximidad y colindancia, y encuentra apoyo en las modernas concepciones que defienden la función social de tal derecho. Ha sido el denominado Derecho de Vecindad el que se ha ocupado de definir y fijar estos límites, distinguiéndose dos clases de relaciones vecinales, cuyos efectos jurídicos difieren sutilmente: 
- las de contenido predeterminado y eficacia real y

- las que poseen un relieve obligacional.

Por vía doctrinal y jurisprudencial se han delineado los caracteres generales de esta figura, diferenciándose las típicas relaciones vecinales de las servidumbres, con las que usualmente se les confunde. Tales confusiones, originadas desde la configuración legislativa que exhibía el $C C$ español de 1888 , se han mantenido en el escenario legislativo cubano actual, propiciado por las regulaciones contenidas en el vigente $C C$ cubano, en cuyo marco de regulación normativa de las "limitaciones derivadas de las relaciones de vecindad" se tutelan clásicas servidumbres como lo es la de paso necesario. Es oportuno razonar, sin embargo, que las imprecisiones que haya podido cometer el legislador en modo alguno pueden provocar una desnaturalización de estas instituciones al punto que conlleve a su confusión; pues ello implicaría mezclar los efectos jurídicos derivados de una y otra que, obviamente, son diferentes.

Sobre la prescripción extintiva $y$ se eficacia en conflictos vecinales, tema central de la presente investigación, puede concluirse que este instituto-que encuentra justificación en los principios de certidumbre y seguridad jurídica-, resulta plenamente aplicable en los conflictos generados por razón de la vecindad, de tal suerte que la inacción por quien se estime afectado por una perturbación causada por el vecino, durante el plazo que prevé la ley, hace sucumbir las facultades de exigir vinculadas al derecho subjetivo, imposibilitando su defensa en la vía jurisdiccional, quedando su titular, en última instancia, a expensas de que quien ganó la prescripción cumpla de modo convencional la obligación natural de respetarlo. Valga aclarar que el inicio del cómputo del plazo prescriptivo de la acción, para reclamar perturbaciones derivadas de las relaciones de vecindad, comienza con el momento en el cual surge un estado de hecho que constituye una contradicción del Derecho, y que provoca que la acción sea "legalmente" ejercitable, sin que importe que de hecho no pueda ser interpuesta por su titular.

Con relación al criterio que sustenta la presunta eficacia excluyente de los actos meramente tolerados respecto a la prescripción extintiva en conflictos vecinales, puede sostenerse su absoluta inexactitud; pues ninguna relación existe entre ambos institutos en tanto la doctrina de los actos meramente tolerados se vincula a la posesión y, por consiguiente, al instituto de la prescripción adquisitiva o usucapión. De modo que configurada la excepción de prescripción de la acción frente a una pretensión deducida en un proceso sobre limitaciones derivadas de las relaciones de vecindad, no podrá desestimarse aquélla bajo el fundamento de que la actuación del demandado se inscribe dentro de los actos meramente tolerados, pues con esta no se pretende adquirir un derecho, sino impedir la defensa de aquél en la vía jurisdiccional tras sucumbir, por el paso del tiempo, la facultad de exigir que respecto a él ostentaba su titular. 


\section{BibLIOGRAFÍA CITADA}

Albadalejo, Manuel (1993). Comentarios al Código Civil y Compilaciones Forales. Madrid: Editorial Revista de Derecho Privado, tomo xxv, vol. 1.

Albaladejo, Manuel (2002). Derecho Civil, Introducción y Parte General. Barcelona: Librería Bosch, tomo I.

Boletín del Tribunal Supremo Popular (2001), Madrid.

De la Oliva Santos, Andrés y Miguel A. Fernández López (1990). Derecho Procesal Civil, Madrid, Editorial Ceura. vol. I.

De Pablo Contreras, Pedro (1995). "Prescripción de las acciones reales y usucapión". Cuadernos de Derecho Judicial. Prescripción y caducidad de derechos y acciones. Madrid: Consejo General del Poder Judicial, tomo XIV.

Dízz-Picazo, Luis (1964). La prescripción en el Código Civil. Barcelona: Editorial Bosch.

Díez-Picazo, Luis et al. (1991). Comentario del Código Civil. Madrid: Ministerio de Justicia, tomo II.

Diez Picazo, Luis y Antonio Gullón (1997). Sistema de Derecho Civil. Derecho de cosas y Derecho inmobiliario registral. $6^{\text {a }}$ ed. Madrid: Editorial Tecnos, vol. III.

D'ors, Álvaro (1968). Derecho privado romano. Pamplona: Ediciones Universidad de Navarra.

Fernández Martínez, Marta (2004). "Apuntes sobre la propiedad y los derechos reales en Cuba", en VV. AA. Formación Jurídica para cuadros del Estado. La Habana: Editorial Félix Varela.

FERNÁndeZ URZAindui, Francisco Javier (1994). "Las relaciones de vecindad entre fundos en el Derecho Civil común y foral", en Cuadernos de Derecho Judicial. Madrid: Consejo General del Poder Judicial, tomo IX.

Fernández UrZainqui, Francisco Javier (1995). "La interrupción de la prescripción extintiva". Cuadernos de Derecho Judicial. Prescripción y caducidad de derechos y acciones. Madrid: Consejo General del Poder Judicial, tomo XIV.

García Cantero, Gabriel (1995). "El instituto de la prescripción y sus orientaciones en el Derecho Comparado". Cuadernos de Derecho Judicial. Prescripción y caducidad de derechos y acciones. Madrid: Consejo General del Poder Judicial, tomo XIV.

Hernández Gil, Antonio (1985). Las relaciones de vecindad en el Código Civil. Madrid: Real Academia de la Jurisprudencia y la Legislación.

Lacruz Berdejo, José Luis (2008). Elementos de Derecho Civil. Derechos reales, posesión y propiedad. Madrid: Editorial Dykinson, tomo III, vol. I.

Larenz, Karl (1978). Derecho Civil, Parte General. Madrid: Editorial Revista de Derecho Privado.

Muñoz Jiménez, Francisco (1995). "El inicio de la prescripción y el cómputo de sus plazo". Cuadernos de Derecho Judicial. Prescripción y caducidad de derechos y acciones. Madrid: Consejo General del Poder Judicial, tomo XIV.

Pérez Gallardo, Leonardo B. (2001). Código Civil de la República de Cuba. Anotado y concordado. La Habana: Editorial Ciencias Sociales.

Rapa Álvarez, Vicente (1988). "La relación jurídica. Categoría esencial en el nuevo Código Civil". Revista Jurídica del Ministerio de Justicia. La Habana, abril-junio. 
Rivero Valdés, Orlando (2003). Temas de Derechos Reales. La Habana: Editorial Félix Varela.

SAnagustín Sánchez, Jesús (2011). "Las relaciones de vecindad en el Código del Derecho Foral de Aragón: luces y sombras". Revista de Derecho Civil Aragonés. vol. XVIII, No 2. Zaragoza.

Sancho Rebullida, Francisco (1967). "Derecho de bienes, relaciones de vecindad, servidumbres". Boletín del Colegio de Abogados de Zaragoza.

Valls Gombau, José Francisco (1995). "Tratamiento procesal de la prescripción extintiva y caducidad. Aspectos prácticos en el ejercicio de las acciones ante los tribunales en la sustanciación del proceso". Cuadernos de Derecho Judicial. Prescripción y caducidad de derechos y acciones. Madrid: Consejo General del Poder Judicial, tomo XIV.

\section{Normas citadas}

Ley $\mathrm{N}^{\circ} 7 / 1977$, de 19 de agosto; modificada por el decreto ley $\mathrm{N}^{\circ}$ 241/ 2006, de 27 de septiembre. Ley de Procedimiento Civil, Administrativo, Laboral y Económico.

Ley No 59/1987 de 16 de julio. Código Civil de la República de Cuba.

Código Civil español. Aprobado por real decreto de 24 de julio de 1889. 